\title{
Book Review: \\ Andrea Staiti, Etica naturalistica e fenomenologia \\ Bologna, Il Mulino, 2020 \\ 160pp.
}

\author{
Sara Dameno \\ University of Bologna \\ sara.dameno2@unibo.it
}

With his book, Etica naturalistica e fenomenologia, Andrea Staiti succeeded in disproving an old prejudice about Husserlian scholarship, namely that phenomenologists are more interested in studying phenomenology rather than practising it. In fact, in his work, he takes part in the contemporary metaethical debate facing its main topics and issues from a phenomenological perspective. The book presents four chapters, each of which deals with central metaethical themes or theories and their possible phenomenological interpretation. Staiti's work, then, comes as a necessary contribution to contemporary philosophy under several perspectives. First, his book tries to close the gap between contemporary metaethics and phenomenology, and, in doing so, it succeeds in being a text that works for all, namely for both phenomenology and metaethics scholars. Despite the complexity of the phenomenological concepts introduced, Staiti never loses clarity, making the book suitable even for readers with no phenomenological background. The same happens in the case of metaethics: he always presents the most significant trends in present-day research and accomplishes a precise reconstruction of central debates around the core issues. Moreover, as Staiti states, the book has a double aim. In addition to the explicit intent to introduce phenomenology in contemporary metaethical research, the book implicitly attempts to strengthen this debate in the Italian philosophical scene too (p. 8). During the twentieth century, few Italian authors dealt with issues of metaethics, and they were not aware of the latter as an autonomous 
discipline (p. 7). Thus, today a more developed debate in the area is still a desideratum.

As the book's title reveals, Staiti wants to dialogue with a specific philosophical view: naturalism. At first glance, the combination of phenomenology and naturalism sounds, especially for phenomenologists, quite bizarre. However, the label 'naturalism' without further specification is misleading. That is why Staiti explores the notion of naturalism in depth, considering all its implications for his future philosophical analyses. In other words, the preliminary work of $\S \S 1-3$, Chap. 1 accounts for three different problems: (1) the role of naturalism for philosophy in general; (2) the implications for ethics of the endorsement of a specific naturalistic stance; (3) the way according to which a naturalistic or non-naturalistic approach characterises most of the metaethics debate.

By clarifying the notion of naturalism, Staiti sets an essential premise for future chapters. Generally, naturalism raises questions about the relation between science and philosophy. The most common way to define this connection is through a «metaphor of continuity» (p. 15). However, when it comes to clarifying the nature of this continuity, there is no general agreement. Staiti lists different (failing) attempts to achieve that definition, for example, a methodological continuity (methodological naturalism), or an ontological/metaphysical continuity (ontological naturalism) (pp. 15-18). However, he reaches the crucial point of his analysis in discussing the contraposition between scientific naturalism and what he calls, following De Caro, liberalised naturalism (pp. 18-19). While the former seems to admit no other paradigm for the interpretation of reality than that of «hard» natural sciences, liberalised naturalism establishes a more balanced relationship between the roles of science and philosophy. More specifically, liberalised naturalism rejects the metaphor of continuity and the idea that philosophy must refer only to scientific work. Nonetheless, it can be defined as a naturalism to the extent that a) it rejects supernatural events in philosophy; b) it seeks to combine scientific rationality with philosophical one (p. 20).

The examination of various types of naturalisms and the choice of liberalized naturalism, as the ideal starting point for philosophical research that intends to work in harmony with scientific thought, has important implications for ethics. Usually, ethical naturalism refuses the assumptions that ethics must 
be a study area (i) independent from all considerations regarding those natural properties that hold our actions up; (ii) founded entirely a priori (p. 25). However, it rejects any reference to supernatural events, namely entities that violate natural laws (p. 23). Another fundamental assumption is the realistic position concerning moral facts: there are moral facts, and they can be recognized in a similar way as natural ones; that is to say, when we talk about moral phenomena, we refer to states of affairs in the world (pp. 12, 23). In this way, it is possible to avoid distortions of moral phenomena such as those entailed by scientific naturalism, expressivism, or non-cognitivism (pp. 21-22).

From this moment on, Staiti examines all the metaethical issues presented through the lens of naturalism or non-naturalism (and later through the phenomenological one). The two trends usually disagree on the nature of moral facts (p. 26). While for naturalists, moral facts are accessible in the same way as natural ones, for non-naturalists, this is profoundly incorrect. On the contrary, non-naturalists argue that although moral facts sometimes depend on natural ones, their nature is essentially different since they do not exist in the same way as the former. Furthermore, they claim that while natural concepts are descriptive, moral ones are purely normative (pp. 26). There have been several attempts in metaethical debates to find common ground for the two views (pp. 28-29). However, only a supervenient relationship seems to have achieved this goal: both naturalists and non-naturalists accept it as linking moral properties and natural ones. Supervenience implies that the former vary if the latter do so (p. 28). Nonetheless, according to Staiti, there is a third way to approach such metaethical issues: the phenomenological one. Phenomenology seems to synthesize the best intuitions of both naturalism and non-naturalism in a unitary frame. Simultaneously, it manages to overcome various difficulties often caused by a one-sided approach towards problems or generated by an uncritical assumption of certain postulates, rather than by the topic's nature. In the following three chapters, Staiti deals with some crucial metaethical issues, attempting a possible phenomenological resolution of them. To achieve this, he deploys sizeable phenomenological equipment in facing topics such as moral perception and moral intuition (Chapter 2); supervenience (Chapter 3); and, finally, Moore's Open Question Argument (Chapter 4).

In $\S 5$, Chap. 1, Staiti establishes a parallel between phenomenology and liberalised naturalism. They both share the assumption that axiological 
properties are accessible through experience, namely that they can be perceived as natural ones (p. 37). However, when it comes to elaborating a perceptual model that accounts for such experience, contemporary analyses on moral perception and phenomenology diverge on fundamental assumptions. In $\S 1$, Chap. 2, Staiti presents Robert Audi's work on the topic (pp. 44-46). Although there are various similarities, Audi's theory differs from a phenomenologicalintentional perceptual approach since it is a form of causal representationalism. Representationalism presents several difficulties for perception per se and moral perception as well (pp. 46-49). On the contrary, an intentional theory of perception entails benefits for both. Firstly, phenomenology rejects representationalism, namely the idea that perception entails a causal process that leads to a duplication of the object, one internal and one external. In contrast, perception implies only one object: the perceived as such (pp. 50-51). Hence, no more risks for infinite regress (p. 48). Furthermore, there is no need to account for the perception of moral properties that are not pictorially representable (p. 54). Secondly, the intentional relation between the subject and the object is not causal nor representational; it is a manifestative relationship (p. 54). In a phenomenological perspective, representationalism confuses direct perception with the reflection on such perception, mistaking the object emerging from the latter as an internal representation of the object of the former (p. 54). Thus, the intentional-perceptional model avoids some naturalistic difficulties but maintains naturalism's fundamental assumption: axiological properties are accessible through experience.

Phenomenology has a lot to say about the non-naturalistic positions as well. In $\S 2$, Chap. 2, Staiti works on intuitionists' central theses. Classic intuitionists (such as Moore, Ross, Prichard) argued that moral properties are accessible through a priori intuition, using it as an anti-naturalistic argument. However, due to the general acceptance of the supervenience relationship, present-day intuitionists focus on the relationship between natural and moral properties, rather than moral properties per se as intuition objects (p. 61). In phenomenology, both the notion of intuition and a priori are crucial concepts; nevertheless, their meaning is entirely different from those entailed by the contemporary metaethical debate. Firstly, Husserl's phenomenology reformulates the notion of a priori. It is no longer an innate structure of reason, nor does it indicate anteriority concerning experience. The phenomenological 
a priori is material, that is, it gives shape to objects and experiences of a specific region of reality. Thus, independence from experience means that no future experiences can modify this structure (pp. 38-39). Therefore, the material a priori maintains the moral sphere's a priori character without ignoring experience as its way of access. Secondly, Staiti shows how phenomenological intuition differs from contemporary philosophers' one. Both naturalists and anti-naturalists consider intuition a sui generis experience, even if characterized in various ways (p. 60). On the contrary, for phenomenology intuition is (a) the final step of a cognitive process (p. 65); (b) the epistemic characterization of an experience (perceptive, judgmental, emotional) (p. 66). It is always a form of identification between the «sense merely intended» and the «sense actually perceived» (p. 63). Epistemically valid, and as long as they remain so: intuitions need no further justification (p. 66).

Phenomenological intuition can help clarify those intuitive experiences evoked in the contemporary philosophical debate, such as self-evident propositions, thought experiments, and the supervenience relationship (pp. 6162). Regarding self-evident propositions, Husserl also recognises them as cases of intuition in both ethics and logic. However, this set of experiences is very narrow: it contains all self-evident propositions that constitute the minimal formal framework that needs to be respected in order to formulate any possible truth-claiming proposition (pp. 68-69). Instead, the insights that mental experiments cause are, phenomenologically, nothing more than thoughts; namely, empty «intentions» associatively reawakened and based on previous experiences and their horizons of anticipation (p. 69). Scenarios presented in mental experiments reawaken the participant's previous experience and prompt her to formulate her answer or opinion on the situation (p. 70). Therefore, intuition is no longer an immediate grasp of truth: it is an empty intention asking for fulfilment that can vary between different participants and their wealth of experience (or according to experiments' integrations) (p. 74).

As mentioned before, both intuitionists and naturalists embrace the supervenience relationship. Thus, Staiti's aims for Chapter 3 are: (i) explaining how the phenomenological approach avoids an "additive" notion of supervenience; (ii) showing a phenomenological criterion to distinguish between the class of natural properties and the class of axiological ones; (iii) providing a phenomenological hypothesis for the interpretation of 
supervenience. Staiti starts from McPherson's general definition of supervenience: a covariance relation between pairs of property classes that enjoys reflexivity, transitivity, and non-symmetry (p. 77). Nevertheless, commentators develop this definition according to different aspects, as in the case of local supervenience (McPherson) and global supervenience (Ridge) (p. 78). Furthermore, they proposed various hypotheses on the relationship's nature (such as the identity hypothesis or the grounding hypothesis) (p. 80). However, Staiti stresses an awkward gap in the contemporary supervenience debate: philosophers focus entirely on defining supervenience's characteristics, without questioning the very nature of those proprieties that it should connect (p. 81). They assume the distinction between natural and moral properties (namely between subvenient and supervenient properties) as evident. On the contrary, Husserl's phenomenology is a valuable source of analysis about the nature of values and axiological experiences.

Phenomenological analysis of axiological properties relies on a specific class of acts, the emotional ones. Thus, Staiti first introduces two distinctions made by Husserl in the $V$ Logical Investigation, valid for the life of consciousness in general and crucial to define emotional acts' nature: (a) the matter and the quality of an act; (b) objectifying acts and non-objectifying acts (pp. 82-84). Emotional acts are intentional, namely consisting of a matter and a quality. However, they are non-objectifying, in the sense that they cannot provide a positional qualification (i.e., reality or fantasy) for their matters; therefore, as non-objectifying acts, they are based on objectifying ones; the latter give qualification to the matter (pp. 85). The foundation of nonobjectifying acts (in our case the emotional ones) in the positional work of objectifying acts ensures a non-additive conception of axiological properties. Experience presents itself as an axiologically qualified whole from the beginning: the distinction between axiological properties and their natural basis results from subsequent analyses (p. 58). Such analyses entail a change in the attitude of the researcher (p. 91). The notion of attitude has technical phenomenological meaning; namely, it indicates an overall orientation of the life of consciousness that opens up a specific possible experiential horizon (See Hua VI, pp. 318-19). Generally, experience presents itself from the beginning as axiologically connoted since the subject lives primarily in a personalistic attitude (Hua IV, § 49). By modifying such attitude, both the axiological and 
the natural (or «logical») properties can be analysed individually. Husserl provides a simple criterion to distinguish between subvenient logical properties and supervenient axiological ones, overcoming another difficulty in the contemporary debate. Logical properties are the basis on which axiological ones rest: indeed, it is possible to abstract axiological qualities of an object, but not its logical qualities. The latter are those properties without which the object of a given ontological region would cease to exist as such; they guarantee its unity as an object (p. 92).

Finally, Staiti compares contemporary supervenience with the phenomenological notion of foundation (pp. 99-ff.). In phenomenology, the link between axiological properties and logical ones is a motivational relationship. Motivation is not a causal link, even though it works in the spiritual world (disclosed in the personalistic attitude) as causality does in the natural one (Hua IV, § 56). As Staiti explains, in the relation between axiological and logical properties, motivation arises when the subject of experience is led by the object's logical properties (but not only) to ascribe specific axiological properties to it. The motivational relationship becomes a purely noetic solution, an eidetic lawfulness, to account for the link between these two classes of properties.

In Chapter 4, Staiti accomplishes a phenomenological interpretation of one of the most famous metaethics tradition arguments: Moore's Open Question Argument (OQA). According to the latter, good is a simple and, thus, nondefinable notion. Staiti highlights mainly two OQA's implications: (1) the question of whether $\mathrm{x}$ is good is always open; namely, independently form how we define 'good', it is always reasonable to ask whether what fulfils such definition is good; (2) every substitution of the predicate 'good' in a proposition alters its meaning irremediably (p. 124). Staiti leans on Peter Geach's criticism towards the OQA. Following his distinction between attributive and predicative adjectives, he accepts the intuition that 'good' has an attributive use, rather than a predicative one (pp. 124-125). It qualifies the referent, but without adding a new character to the list of its properties. Nonetheless, Geach does not provide any other element to account for the normative character of such predicate. Here phenomenology comes into play again. First, Staiti shows that 'good' is not the only predicate that entails an open question. It happens in the case of the existential predicate too (Chap. $4, \S 3$ ). That is because existence, 
good, and beautiful are specific normative predicates; the latter are variations of the 'true' predicate in reason's different spheres (Hua XXVII, pp. 268-69). Now, phenomenologically speaking, all these normative predicates do not refer to objects, but to their corresponding posita (Sätze) (p. 130). The notion of positum, crucial for the subsequent interpretation of the OQA, indicates the union of the «object's sense» and its «thetic character» (in Logical Investigations's terms, the union of the «act's matter» and its «positional qualification») (p. 131). It is always the result of a subsequent reflective analysis of experience and never correlated with an immediate experience, always directed towards objects or states of affairs. As Staiti states, posita are the subject's claims towards reality, legitimate if they receive an intuitive fulfilment (p. 133). In this sense, Staiti interprets both the open questions, the existential one and the Moorean one, as questions regarding the intuitive fulfilment of the positum intended. The Moorean question "if $\mathrm{x}$ is good" always remains open, not because the notion of good is simple and indefinable, but because good is a normative predicate and it is always possible to ask whether an intuitive fulfilment of the object's axiological qualities takes place or not (pp. 137-138). Therefore, phenomenology succeeds again in bringing together the best insights of contemporary metaethical debate in a unified framework. On the one hand, it conserves Moore's intuition about the impossibility of defining good as a natural property. On the other, it does not neglect Geach's criticisms regarding Moore's failure to recognise the logical difference between attributive adjectives as good and predictive ones (p. 142).

In conclusion, it is fair to say that Staiti's book is an excellent example of phenomenological philosophy in action. His broad knowledge of contemporary metaethics and the theoretical elegance with which he handles thorny phenomenological themes make his publication a relevant contribution to contemporary philosophy. 